OPEN ACCESS

Edited by:

Fu Lijun,

Shanghai Children's Medical

Center, China

Reviewed by:

Muhammad Ali Mumtaz,

Baylor College of Medicine,

United States

Federico Gutierrez-Larraya,

University Hospital La Paz, Spain

${ }^{*}$ Correspondence:

Ying Liao

liaoyingwww@163.com

Junbao Du

junbaodu1@126.com

tThese authors have contributed equally to this work

Specialty section

This article was submitted to

Pediatric Cardiology,

a section of the journal

Frontiers in Pediatrics

Received: 01 June 2019

Accepted: 31 July 2019

Published: 16 August 2019

Citation:

Li Y, Yu Y, Chen S, Liao Y and Du J

(2019) Corticosteroids and

Intravenous Immunoglobulin in

Pediatric Myocarditis: A

Meta-Analysis. Front. Pediatr. 7:342.

doi: 10.3389/fped.2019.00342

\section{Corticosteroids and Intravenous Immunoglobulin in Pediatric Myocarditis: A Meta-Analysis}

\author{
Yining $\mathrm{Li}^{1,2 t}$, Yuqing $\mathrm{Yu}^{1,2+}$, Selena Chen ${ }^{3}$, Ying Liao ${ }^{1 *}$ and Junbao $\mathrm{Du}{ }^{1 *}$ \\ ${ }^{1}$ Department of Pediatrics, Peking University First Hospital, Beijing, China, ${ }^{2}$ Department of Basic Medical Sciences, Peking \\ University School of Basic Medical Sciences, Beijing, China, ${ }^{3}$ Division of Biological Sciences, University of California, San \\ Diego, La Jolla, CA, United States
}

Background: The efficacy of corticosteroids and intravenous immunoglobulin (IVIG) in pediatric myocarditis remains controversial.

Objectives: The authors performed a meta-analysis to assess the therapeutic efficacy of corticosteroids and IVIG in children with myocarditis.

Methods: We retrieved the trials on corticosteroids and IVIG therapy, respectively, in pediatric myocarditis from nine databases up to December 2018. Statistical analysis was performed using Review Manager 5.3.

Results: Our analysis included 8 studies and 334 pediatric patients. The data demonstrated that children receiving corticosteroids showed no significant improvement on left ventricular ejection fraction (LVEF) from 1 to 8 month-follow-up (MD $=5.17 \%$, $95 \% \mathrm{Cl}=-0.26 \%$ to $10.60 \%, P=0.06$ ), and no significant improvement in death or heart transplantation incidence at the end of follow-up $(\mathrm{OR}=1.33,95 \% \mathrm{Cl}=0.27-6.70$, $P=0.73$ ). However, children receiving IVIG revealed a statistically remarkable increase in LVEF at a follow-up over the course of 6 months to 1 year (MD $=18.91 \%$, 95\% $\mathrm{Cl}=11.74-26.08 \%, P<0.00001)$, and a decrease in death or heart transplantation at the end of follow-up (OR $=0.31,95 \% \mathrm{Cl}=0.12-0.75, P=0.01)$. Further comparisons showed that the mortality and heart transplantation rate of children with myocarditis treated with IVIG were significantly lower than those with corticosteroid therapy (t' $=11.336, P<0.001)$.

Conclusions: IVIG might be beneficial to improve LVEF and survival for myocarditis in children. However, the present evidence does not support corticosteroids as superior to conventional therapy in children with myocarditis. Further randomized controlled trials with a larger sample size are required.

\section{Keywords: myocarditis, children, corticosteroid, intravenous immunoglobulin, meta-analysis}

\section{INTRODUCTION}

Myocarditis is generally defined as the inflammatory cellular infiltration in the myocardium and subsequent cardiomyocyte necrosis of non-ischemic origin according to Dallas criteria $(1,2)$. It has a variety of clinical presentations (3). The exact incidence of myocarditis in children remains unknown (1). A multi-institutional analysis by Klugman et al. showed that myocarditis took up 
about $0.05 \%$ among pediatric hospital discharges in the United States (4). Towbin and colleagues reported that the incidence of dilated cardiomyopathy (DCM) in children was 0.57 cases per 100,000 per year overall, $46 \%$ of which were caused by myocarditis (5). It is estimated that the prevalence of pediatric myocarditis is 0.3 cases per year per 100,000 children (6). Although myocarditis is not common in children, it can lead to significant morbidity and mortality (5).

It is generally believed that viral infection is a major cause of myocarditis. The pathophysiology of myocarditis consists of direct viral injury from viral proteins, the innate immune response including cytokines, toll-like receptors, and complements, and the acquired immune response involving $\mathrm{T}$ cells and antibodies. A chronic immune reaction related to molecular mimicry may lead to chronic dilated cardiomyopathy even without solid evidence of viral persistence (3, 7-9). Immunosuppressive therapy such as corticosteroids has been used in patients. In experimental models and some uncontrolled cases of myocarditis, intravenous immunoglobulin (IVIG) has shown to have antiviral and immunomodulatory effects (1). However, the efficacy of corticosteroids and IVIG remains controversial. Limited trials have been conducted on children, and the results are inconsistent. We therefore performed a meta-analysis of all qualified randomized or non-randomized controlled trials to determine the therapeutic efficacy of corticosteroids and IVIG in children with myocarditis.

\section{METHODS}

This meta-analysis was performed following the Preferred Reporting Items for Systematic Reviews and Meta-Analyses (PRISMA) statement (10).

\section{Protocol of Searching}

Studies were confirmed by searches from medical libraries or electronic reviews of published medical literature in our meta-analysis. The databases, including Cochrane (1943-2018), PubMed (1968-2018), Web of science (1970-2018), EMBASE (1991-2018), Chinese Biomed Database (1978-2018), the Latin American and Caribbean Health Science Information Database (LILACs) (1982-2018), the Cumulative Index to Nursing and Allied Health Literature (CINAHL) (1982-2018), WANFANG (1980-2018), and CNKI (1990-2018), were independently searched by two authors using medical subject heading (MeSH) terms (in English or Chinese) such as "myocarditis/inflammatory cardiomyopathy/dilated cardiomyopathy/carditis AND immunoglobulins/gammaglobulin/gamma-globulin/IVIG,"

"myocarditis/inflammatory cardiomyopathy/carditis

AND cardiomyopathy/dilated agents/glucocorticoids/immunosuppressive agents/adrenal cortex hormones/predniso/dexamethason/hydrocortiso/

Abbreviations: IVIG, intravenous immunoglobulin; DCM, dilated cardiomyopathy; LVEF, left ventricular ejection fraction; RCT, randomized controlled trial; ECMO, extracorporeal membrane oxygenation; $\mathrm{MD}$, mean difference; CI, confidence interval; OR, odds ratio; SD, standard deviation; SE, standard error. methylprednison/steroid/corticostero/immunosuppress/ glucocorticoid/mineralocorticoid/betamethason/budesonide/ cortiso/fludrocortiso." We also narrowed the spectrum using the filters of clinical trial and child in the search strategy. No language restrictions were applied. Original articles were acquired from electronic databases or libraries.

\section{Study Inclusion Criteria}

We included English or Chinese studies that referred to randomized or retrospective conventional therapy-controlled trials for the treatment of myocarditis or DCM into our analysis. The diagnosis of myocarditis was made by established clinical, echocardiographic, cardiac MRI, histological, immunological, and immunohistochemical criteria. Trials involving Kawasaki disease, structural heart disease and other specific causes of acute cardiomyopathy as sepsis or drug toxicity were excluded. IVIG, corticosteroids or IVIG in combination with steroid agents were given to the treatment group while traditional therapy was used on the control group. The general characteristics of the subjects, the protocol of the trials and the process of the follow-up were illuminated in detail. Indicators for evaluating effects included the recovery of heart function after undergoing treatment, or the rate of death or heart transplantation during follow-up.

\section{Study Exclusion Criteria}

Studies without a clear standard of diagnosis of myocarditis or the use of other drugs in the control group were not selected. Additionally, studies in which subjects were not children, or the endpoints were not clearly described, were also eliminated. Some uncontrolled trials were excluded as well.

\section{Study Quality Assessment}

Two reviewers independently screened the title and abstract, selected the studies and assessed the quality of studies. Characteristics of subjects, design of trials, course of arrangement and analysis were abstracted and rated. Quality assessment of randomized controlled trials (RCTs) were based on the 7-point Modified Jadad Score, including 7 items on randomization, blinding, allocation concealment, withdrawals and dropouts. Studies were of high quality if they got 4 or more points. The quality of enrolled retrospective cohort studies was evaluated by the 9-star Newcastle-Ottawa Quality Assessment Scale, including 8 items on patient selection, comparability and outcome. Studies were interpreted as high-quality studies if they got 5 or more stars. Divergence was resolved by discussion, or by recourse to a third reviewer. Publication bias was assessed by Funnel plot.

\section{Statistical Analysis}

We used the Review Manager 5.3 software (The Nordic Cochrane Centre of The Cochrane Collaboration, Copenhagen, Denmark) available on international evidence-based medicine cooperative network for meta-analysis. We tested the heterogeneity of study data by forest plot, the Q-test as well as $I^{2}$ statistics. In the $Q-$ test, the results of included studies were homogenous if $p>$ 0.05 , and a fixed effect model was applied; while if $p<0.05$, the results were heterogeneous, and the outcome of systematic analysis was stated in a random effects model. $I^{2}>50 \%$ indicated 
a significant heterogeneity. The final results were indicated in the form of vector images which combined mean difference (MD) or odds ratio (OR) with $95 \%$ confidence interval (CI). We also compared the two medicines by weighted independent $t$-test. $P$ $<0.05$ showed a statistically significant difference.

\section{RESULTS}

\section{Basic Data of Included Studies}

A total of 4,546 studies were retrieved using the retrieval methods mentioned above. Finally, there were eight studies (1118) being adopted based on exclusion and inclusion criteria (Figure 1), consisting of two randomized controlled trials and six retrospective studies. All studies were published in English. Table 1 shows the general background of eight studies and the list of characteristics of the subjects such as age. In total, 334 pediatric patients with myocarditis or DCM were included, consisting of 146 patients in the experimental group and 188 patients in the control group. The range of mean age of the research subjects was $0-17.7$ years. All pediatric patients in these studies were diagnosed as myocarditis or DCM with or without corticosteroids or IVIG. Two of the eight studies regarded only left ventricular ejection fraction (LVEF) as the endpoint of follow-up, while four of the studies used only death or heart transplantation to indicate pharmaceutical effect. The remaining studies used both LVEF and death or heart transplantation to reflect the therapeutic efficacy. In studies mentioning the administration time, the mean time for corticosteroids administration varied from 1 to 8 months, while the range of mean time for IVIG administration was from 2 to 5 days. Follow-up duration lasted from 1 month to 5 years. The results of quality assessment showed that six of the eight studies were high-quality studies (Table 1).

\section{Publication Bias}

Funnel plot analysis indicates significant publication bias for the increase in LVEF and death or heart transplantation incidence (Figure 2). The number of articles available is likely a major contributing factor, which also limits our further test for funnel plot asymmetry.

\section{Analysis of Left Ventricular Ejection Fraction}

LVEF of children with myocarditis or dilated cardiomyopathy after intervention was reported in four trials. A total of 157 subjects were included, 81 in the treatment group and 76 in

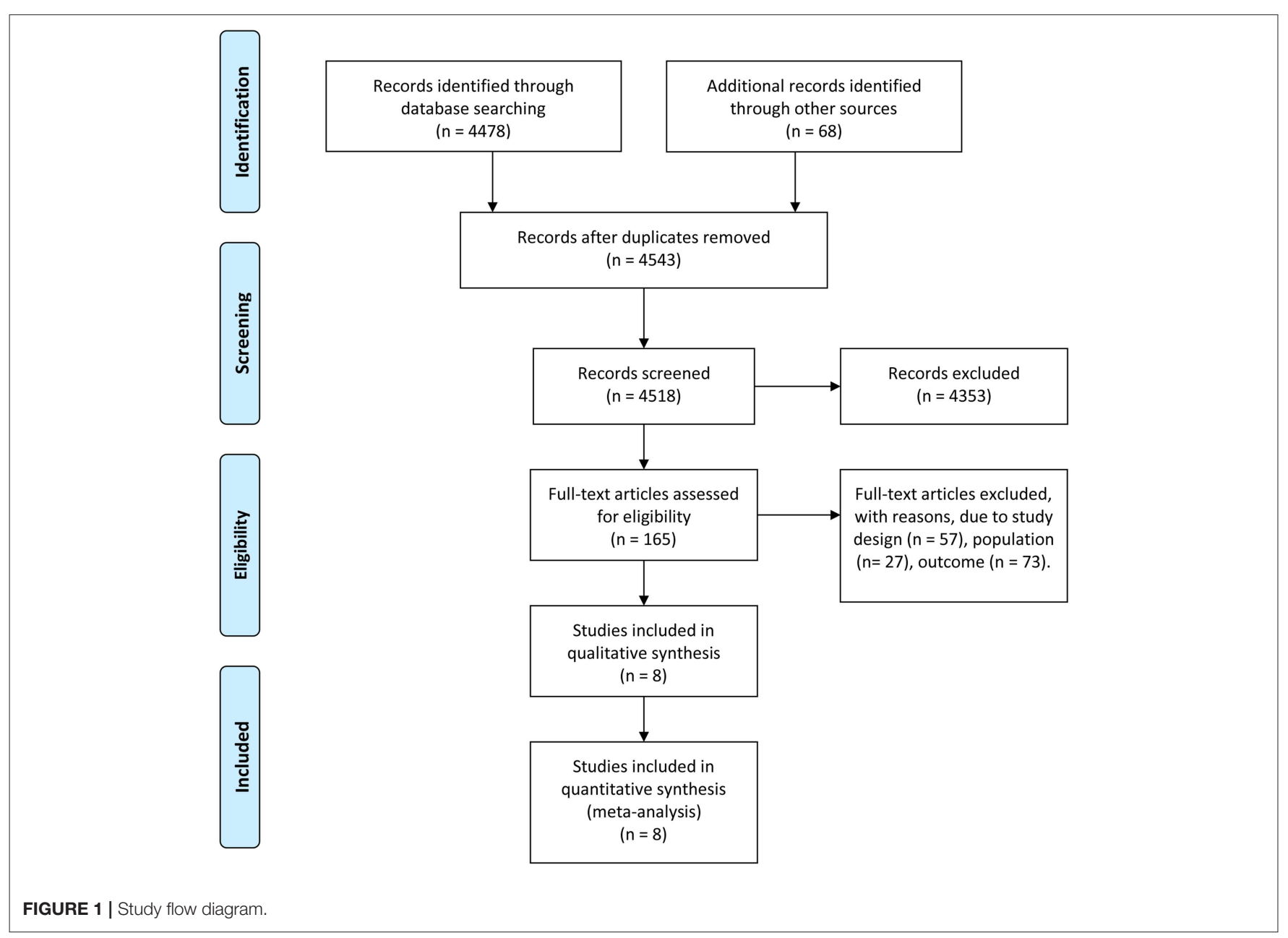


TABLE 1 | Basic data of eight included trials.

\begin{tabular}{|c|c|c|c|c|c|c|c|c|c|c|c|c|c|}
\hline \multirow[t]{2}{*}{ References } & \multirow{2}{*}{$\begin{array}{l}\text { Study } \\
\text { design }\end{array}$} & \multicolumn{2}{|c|}{ Groups } & \multicolumn{2}{|c|}{ Age } & \multirow[t]{2}{*}{ Drugs } & \multirow[t]{2}{*}{ Dosing regimen } & \multirow[t]{2}{*}{ Control } & \multirow[t]{2}{*}{ Endpoint } & \multicolumn{2}{|c|}{ Follow-up duration } & \multirow{2}{*}{$\begin{array}{c}P \text { - } \\
\text { value }\end{array}$} & \multirow{2}{*}{$\begin{array}{c}\text { Quality } \\
\text { assessment }\end{array}$} \\
\hline & & $\mathbf{T}$ & C & $\mathbf{T}$ & C & & & & & $\mathbf{T}$ & C & & \\
\hline Aziz et al. (11) & $\mathrm{RCT}$ & 44 & 24 & $\begin{array}{l}3.4 \pm \\
2.5 \\
\text { years }\end{array}$ & $\begin{array}{l}4.2 \pm \\
3.4 \\
\text { years }\end{array}$ & Prednisolone & $\begin{array}{l}2 \mathrm{mg} / \mathrm{kg} / \text { day for } 1 \\
\text { month and then } \\
\text { tapered off over a } \\
\text { period of } 15 \text { days }\end{array}$ & $\begin{array}{l}\text { Conventional } \\
\text { therapy }\end{array}$ & LVEF & $\begin{array}{l}15.1 \pm \\
9.2 \\
\text { months }\end{array}$ & $\begin{array}{c}13.6 \pm \\
10.6 \\
\text { months }\end{array}$ & 0.06 & 2 \\
\hline $\begin{array}{l}\text { Camargo } \\
\text { et al. (12) }\end{array}$ & $\mathrm{RCT}$ & 12 & 9 & \multicolumn{2}{|c|}{$0-15$ years } & Prednisolone & $\begin{array}{l}2.5 \mathrm{mg} / \mathrm{kg} / \mathrm{day} \text { for } 1 \\
\text { week, } 2.0 \mathrm{mg} / \mathrm{kg} / \text { day } \\
\text { for } 3 \text { weeks, } 1.5 \\
\mathrm{mg} / \mathrm{kg} / \text { day for } 4 \\
\text { weeks, and } 1.0 \\
\mathrm{mg} / \mathrm{kg} / \text { day thereafter }\end{array}$ & $\begin{array}{l}\text { Conventional } \\
\text { therapy }\end{array}$ & $\begin{array}{l}\text { LVEF, } \\
\text { death or heart } \\
\text { transplantation }\end{array}$ & \multicolumn{2}{|c|}{8 months } & $>0.05$ & 3 \\
\hline $\begin{array}{l}\text { English et al. } \\
\text { (13) }\end{array}$ & Retrospective & 16 & 6 & \multicolumn{2}{|c|}{$0-17.7$ years } & Steroids & $\begin{array}{l}2-10 \mathrm{mg} / \mathrm{kg} / \text { day for a } \\
\text { minimum of } 3 \text { days }\end{array}$ & $\begin{array}{l}\text { Conventional } \\
\text { therapy }\end{array}$ & $\begin{array}{l}\text { Death or heart } \\
\text { transplantation }\end{array}$ & \multicolumn{2}{|c|}{60 months } & - & 7 \\
\hline $\begin{array}{l}\text { Alrabte and } \\
\text { Bezanti (14) }\end{array}$ & Retrospective & 13 & 27 & \multicolumn{2}{|c|}{9 months } & IVIG & $0.4 \mathrm{~g} / \mathrm{kg} /$ day for 5 days & $\begin{array}{l}\text { Conventional } \\
\text { therapy }\end{array}$ & LVEF & \multicolumn{2}{|c|}{12 months } & - & 7 \\
\hline Atiq et al. (15) & Retrospective & 16 & 20 & $\begin{array}{l}2.39 \pm \\
3.46 \\
\text { years }\end{array}$ & $\begin{array}{l}2.36 \pm \\
1.75 \\
\text { years }\end{array}$ & IVIG & A single dose of $2 \mathrm{~g} / \mathrm{kg}$ & $\begin{array}{l}\text { Conventional } \\
\text { therapy }\end{array}$ & $\begin{array}{l}\text { Death or heart } \\
\text { transplantation }\end{array}$ & \multicolumn{2}{|c|}{12 months } & 0.2 & 9 \\
\hline $\begin{array}{l}\text { Haque et al. } \\
\text { (16) }\end{array}$ & Retrospective & 12 & 13 & $\begin{array}{l}7.3 \pm \\
5.8 \\
\text { years }\end{array}$ & $\begin{array}{l}12.0 \pm \\
4.9 \\
\text { years }\end{array}$ & IVIG & $\begin{array}{l}2 \mathrm{~g} / \mathrm{kg} \text { over } 16-24 \mathrm{~h} \text { on } \\
\text { day of admission }\end{array}$ & $\begin{array}{l}\text { Conventional } \\
\text { therapy }\end{array}$ & $\begin{array}{l}\text { Death or heart } \\
\text { transplantation }\end{array}$ & \multicolumn{2}{|c|}{-} & 0.04 & 7 \\
\hline $\begin{array}{l}\text { Heidendael } \\
\text { et al. (17) }\end{array}$ & Retrospective & 21 & 73 & $\begin{array}{l}10(1 \\
51) \\
\text { months* }\end{array}$ & $\begin{array}{l}18(2, \\
59) \\
\text { months* }\end{array}$ & IVIG & $\begin{array}{l}2 \mathrm{~g} / \mathrm{kg} \text { within } 2 \text { weeks } \\
\text { after initial presentation }\end{array}$ & $\begin{array}{l}\text { Conventional } \\
\text { therapy }\end{array}$ & $\begin{array}{l}\text { Death or heart } \\
\text { transplantation }\end{array}$ & \multicolumn{2}{|c|}{33 months } & 0.432 & 8 \\
\hline $\begin{array}{l}\text { Prasad and } \\
\text { Chaudhary, } \\
\text { (18) }\end{array}$ & Retrospective & 12 & 16 & \multicolumn{2}{|c|}{$<12$ years } & IVIG & $1 \mathrm{~g} / \mathrm{kg} /$ day for 2 days & $\begin{array}{l}\text { Conventional } \\
\text { therapy }\end{array}$ & $\begin{array}{l}\text { LVEF, death or } \\
\text { heart } \\
\text { transplantation }\end{array}$ & \multicolumn{2}{|c|}{6 months } & $<0.05$ & 8 \\
\hline
\end{tabular}

*Age was given as median (interquartile range).

Retrospective cohort studies were evaluated using 9-star Newcastle-Ottawa Quality Assessment Scale; RCT studies were evaluated using 7-point Modified Jadad Score; conventional therapy includes digitalis, diuretics, vasodilators, etc. T, treatment; C, control; RCT, randomized controlled trial; IVIG, intravenous immunoglobulin; LVEF, left ventricular ejection fraction. 

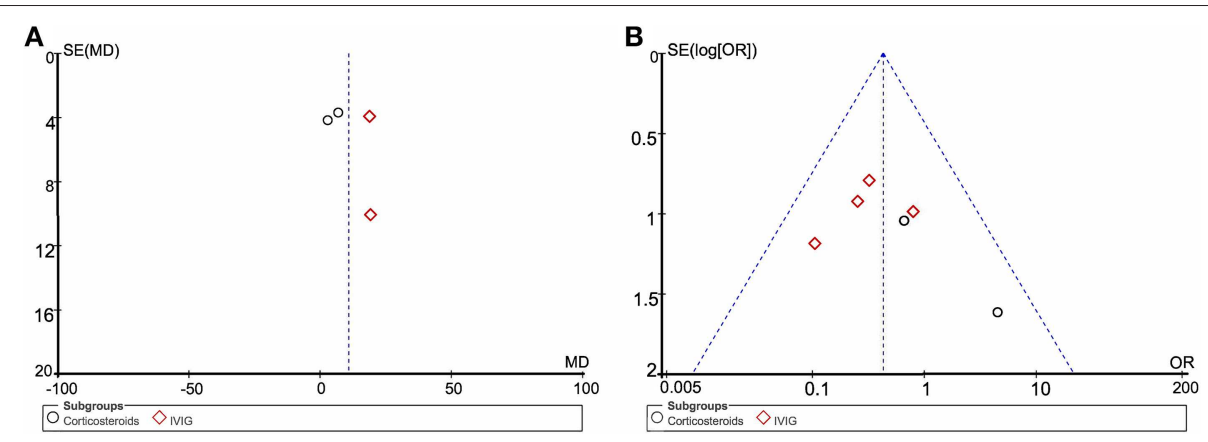

FIGURE 2 | Funnel plot of included studies. (A) The left funnel comprised of four dots representing studies using LVEF as the endpoint. (B) Funnel plot of six clinical trials using death or heart transplantation as the endpoint. MD, mean difference; OR, odds ratio; SE, standard error.

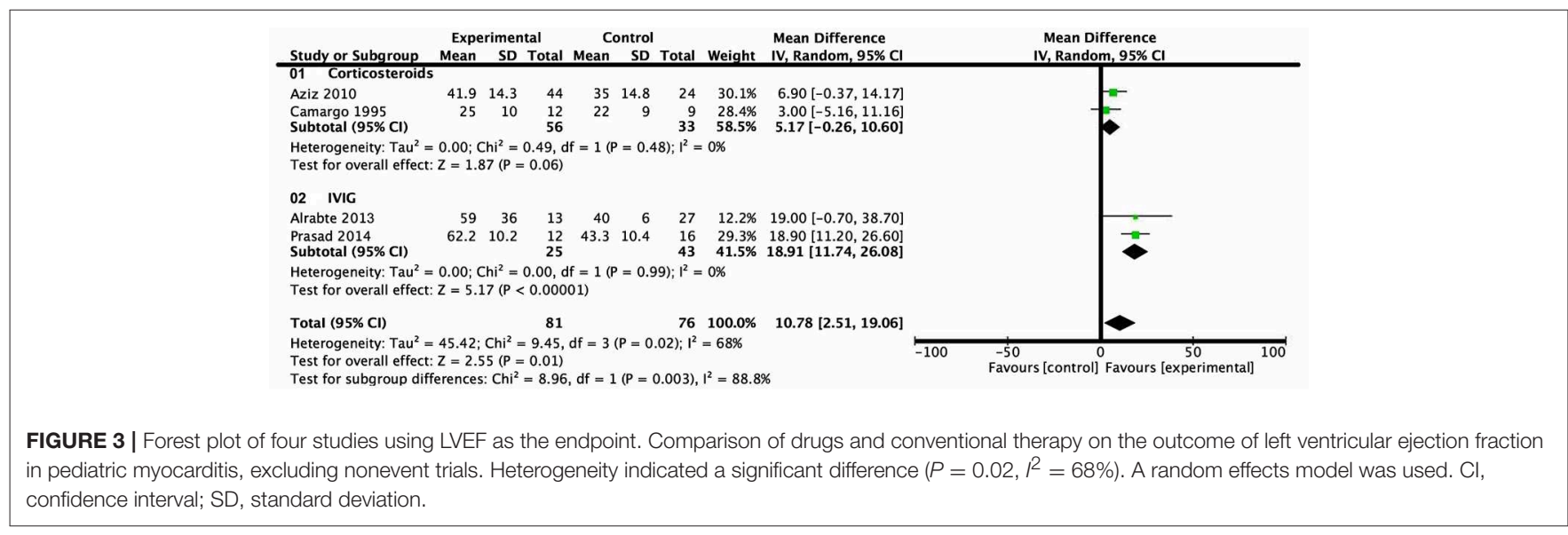

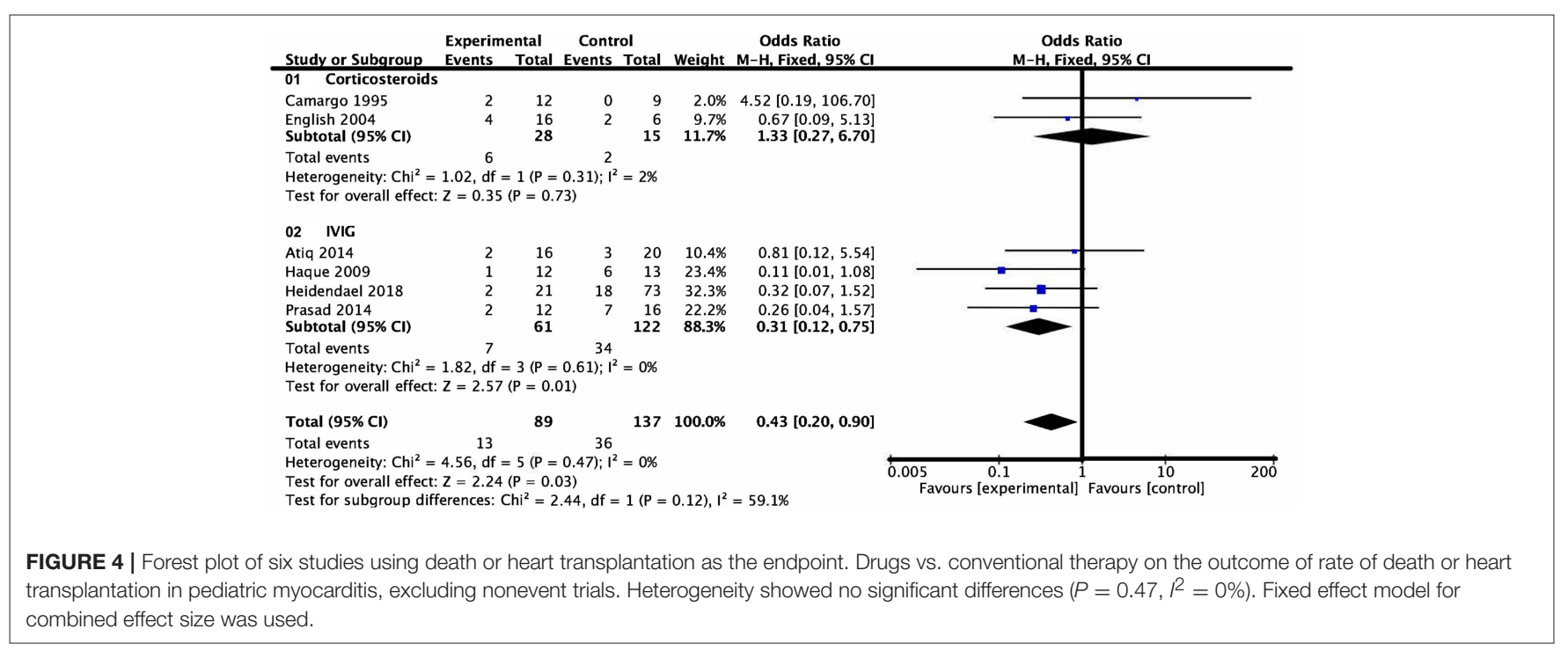

the control group. Heterogeneity analysis showed heterogeneity among the studies $\left(P=0.02, I^{2}=68 \%\right)$ and a random effects model was used. Subgroup analysis showed that there was no statistical difference between the group treated with corticosteroids and the group treated with conventional therapy from 1 month- to 8 month-follow-up (mean difference $=5.17 \%$,
95\% CI $=-0.26 \%-10.60 \%, P=0.06)$. Patients treated with IVIG, on the other hand, revealed a higher level of LVEF compared with patients who received conventional therapy from a follow-up over the course of 6 months to 1 year (mean difference $=18.91 \%$, 95\% CI $=11.74-26.08 \%, P<0.001)$ (Figure 3). 


\section{Analysis of Death and Transplantation}

Six studies assigned death or heart transplantation as the endpoint of investigation, in which investigation of 49 patients ended with death or heart transplantation. This consisted of 13 patients in the medication group and 36 patients in the control group. Heterogeneity analysis showed no heterogeneity among the studies $\left(P=0.47, I^{2}=0\right)$ and a fixed effect model was used. The death or heart transplantation incidence was lower in the medication group than that in the control group $(\mathrm{OR}=0.43,95 \%$ $\mathrm{CI}=0.20-0.90, P=0.03)$. According to the subgroup analysis of the two types of drugs, the death or heart transplantation incidence in pediatric patients treated with IVIG was lower than that of patients treated with conventional therapy at the end of follow-up (OR $=0.31,95 \% \mathrm{CI}=0.12-0.75, P=0.01)$. On the contrary, there was no evidence of a significant difference in the death or heart transplantation incidence between the corticosteroids group and conventional therapy group at the end of follow-up $(\mathrm{OR}=1.33,95 \% \mathrm{CI}=0.27-6.70, P=0.73)$ (Figure 4).

Further comparisons showed that the mortality and heart transplantation rate of children with myocarditis treated with IVIG were significantly lower than those with corticosteroid therapy $\left(t^{\prime}=11.336, P<0.001\right)$ (Table 2).

\section{DISCUSSION}

The results of our meta-analysis show that there is no significant difference in increased LVEF (from a 1 month- to 8 month- follow-up) and decreased death or heart transplantation incidence (at the end of follow-up) between the use of corticosteroids and that of conventional therapy in children with myocarditis or dilated cardiomyopathy. Compared to conventional therapy, additional IVIG treatment may be beneficial for the improvement of LVEF (at follow-up over the course from 6 months to 1 year) and for a decrease in death or heart transplantation rate (at the end of follow-up).

TABLE 2 | Comparisons of percentages of death and heart transplantation in children with myocarditis treated by corticosteroids and intravenous immunoglobulin.

\begin{tabular}{llcc}
\hline Drugs & Reference & $\begin{array}{c}\text { Percentage of death } \\
\text { or heart } \\
\text { transplantation (\%) }\end{array}$ & $\begin{array}{c}\text { Weighted mean } \\
\text { percentage (\%) }\end{array}$ \\
\hline Corticosteroids & Camargo et al. (12) & 16.7 & $21.4 \pm 4.2$ \\
& English et al. (13) & 25.0 & $11.5 \pm 3.0$ \\
IVIG & Atiq et al. (15) & 12.5 & \\
& Haque et al. (16) & 8.3 & \\
& Heidendael et al. & 9.5 & \\
& (17) & 16.7 & \\
& Prasad and & & \\
& Chaudhary, (18) & &
\end{tabular}

Weighted
independent
$t^{\prime}$-test*

*Weighted by number of the subjects; IVIG, intravenous immunoglobulin.
The comparison between corticosteroids and IVIG in death or heart transplantation incidence reveals a statistical superiority of IVIG therapy.

Potential etiologies of myocarditis include infections, physical agents, toxins, medications, autoantigens and so on (19). Viral and post-viral myocarditis are major causes of dilated cardiomyopathy (1). The spectrum of viruses varies from enteroviruses (especially coxsackievirus), human herpesvirus 6, adenovirus, Epstein-Barr virus to parvovirus B19, hepatitis C and cytomegalovirus both in children and adults. Trypanosoma cruzi is a common cause of myocarditis in Central and South America (20). Our meta-analysis did not include this type of myocarditis because of its distinctive epidemiology, pathogenesis, treatment and management (21). After the initial infection period, patients may develop eosinophilic, lymphocytic, or giant cell/granulomatous inflammation of myocardium (22). Lymphocytic myocarditis is the most common viral myocarditis (9). Manifestations of myocarditis differ in children. Signs and symptoms can be sub-clinical, while patients sometimes experience chest pains similar to pericarditis or myocardial infarction, or even undergo sudden cardiac death from ventricular fibrillation. Moreover, symptoms of heart failure might occur when the disease develops into DCM, leading to death or heart transplantation.

The exact mechanisms for the injury during viral myocarditis have been studied for decades. Research on rodent models and isolated cell systems have shown three phases in the pathophysiology. During phase 1, viruses enter myocytes and macrophages through specific receptors and coreceptors and activate the innate immune response. Phase 2 involves viral replication and an acquired immune response. Protein products of viral genomes can also cause damage to myocardium. Phase 3 is either recovery or DCM. Cellular necrosis triggers the host's immune system and causes further degradation. Molecular mimicry possibly plays an important role in this autoimmune response. On most occasions, the status improves as viral titers decrease, whereas in some cases the disease evolves to chronic dilated cardiomyopathy and become irreversible. It is not clear whether viral persistence or reactivation of latent virus is involved in the chronic phase and eventual onset of DCM. Some viruses, such as parvovirus B19, can also cause myocarditis indirectly by infecting cardiac endothelial cells (1, 3, 9, 23). Genetic predisposition possibly works in viral and/or autoimmune myocarditis and later in DCM in humans (2).

The outcome, prognosis, and efficacy of treatment of myocarditis are closely related to etiology, clinical manifestations and the phase of disease. Conventional therapy includes optimal management of arrhythmia and of heart failure. In patients whose conditions deteriorate, mechanical circulatory support is required, such as extracorporeal membrane oxygenation (ECMO) or ventricular assist devices, as a bridge to recovery or heart transplantation.

As immunosuppressants, corticosteroids could be effective in the second phase of myocarditis with the three-phase pathological course. However, our meta-analysis shows that there is no significant difference in LVEF and death or heart transplantation ratio in children between the corticosteroids 
group and the conventional treatment group. Corticosteroids use should depend on a prompt diagnosis and a clear assessment of the stage of myocarditis. In the three studies included, however, corticosteroids use varied among different stages of the patients, which likely resulted in no significant differences. In addition, using corticosteroids in acute myocarditis may exacerbate the situation through immunosuppression during the acute viremic phase (11-13). Although several previous randomized controlled trials $(24,25)$ and meta-analyses (26) have proven the efficacy of corticosteroids, these findings were based primarily on adults. The conclusion may not be conveniently extrapolated to the pediatric population as a result of different etiologies and different physical conditions.

On the other hand, our findings reveal that IVIG may have a therapeutic effect on pediatric myocarditis. Studies have shown that immunoglobulin $G$ and polyvalent intravenous immunoglobulins IgG, IgA, and IgM exert proinflammatory effects, including the activation of immune cells, the complement system, and the opsonization of infective agents. They also have anti-inflammatory effects which comprise the neutralization of bacterial and other toxins, degradation products and an excess of complement factors and cytokines, which help to balance the proinflammatory process (27-29). IVIG can modulate the inflammatory and immune response without major side effects. Thus, if ongoing infection, a post-infectious inflammatory reaction, or a non-infectious process play a role, IVIG can be efficacious (30). However, additional and larger-scale randomized controlled trials on children are necessary for further investigation of IVIG use.

Theoretically, immunosuppressive therapy could lead to sideeffects, including infectious diseases, hypertension, edema, an increase in body weight and so on (26). While IVIG therapy was principally associated with infusion-related side effects, all incidences were reported to be mild (30). We also took adverse drug reaction into account, although it was not comprehensively mentioned in the retrieved articles and reflects a limitation of these studies.

Considering the validity of medication targeting different periods of pathologic process, combination therapy may be a more effective option. However, far less research $(13,31)$ regarding steroid agents combined with IVIG for treating pediatric myocarditis was retrieved. Several studies indicated that combination treatment groups conferred advantages over the control group, while others showed no significant difference in therapeutic effects between the two groups. Therefore, performing more trials to study the efficacy and safety of combined treatment is necessary.

\section{REFERENCES}

1. Cooper LT Jr. Myocarditis. N Engl J Med. (2009) 360:1526-38. doi: 10.1056/NEJMra0800028

2. Caforio ALP, Pankuweit S, Arbustini E, Basso C, Gimeno-Blanes J, Felix SB, et al. Current state of knowledge on aetiology, diagnosis, management, and therapy of myocarditis: a position statement of the European Society
Most previously reported meta-analyses about the treatment for myocarditis $(26,32)$ targeted adults as research subjects. Moreover, most of these mentioned only IVIG or steroid agents, rather than both. On account of the significant morbidity and mortality rates of pediatric myocarditis, it is of great importance to further investigate more effective therapies. Additionally, our meta-analysis compared the efficacy of corticosteroids and IVIG, which might be taken as a reference for further researches.

\section{STUDY LIMITATIONS}

There were some limitations to the present study. The inverted funnel plot demonstrated an existence of publication bias. It is difficult to unify the diagnostic criteria and most studies lacked a clear assessment of the stage of myocarditis. Several different standards for judging the efficacy of medication were not all-inclusive in involved studies so that we could not estimate it completely. In addition, in biopsy-proven virusnegative patients whose condition deteriorates despite optimal conventional management, immunosuppressive therapy should be considered after ruling out the possible contraindications.

\section{CONCLUSIONS}

IVIG might be beneficial to improve LVEF and survival for myocarditis in children. However, the present evidence does not support corticosteroids as superior to conventional therapy in children with myocarditis. Further randomized controlled trials with a larger sample size are required to unambiguously delineate the clinical effect of corticosteroids and IVIG in the treatment of myocarditis in children.

\section{DATA AVAILABILITY}

The datasets generated for this study are available on request to the corresponding author.

\section{AUTHOR CONTRIBUTIONS}

YLi, YY, and JD contributed conception and design of the study. YLi and YY screened the title and abstract, selected the studies, assessed the quality of evidence, extracted the data, and performed the analysis. SC and YLia supervised study selection and data analysis. YLi and YY drafted the initial manuscript. All authors contributed to manuscript revision and read and approved the submitted version.

of Cardiology Working Group on Myocardial and Pericardial Diseases. Eur Heart J. (2013) 34:2636-48. doi: 10.1093/eurheartj/eht210

3. D’Ambrosio A, Patti G, Manzoli A, Sinagra G, Di Lenarda A, Silvestri F, et al. The fate of acute myocarditis between spontaneous improvement and evolution to dilated cardiomyopathy: a review. Heart. (2001) 85:499-504. doi: 10.1136/heart.85. 5.499 
4. Klugman D, Berger JT, Sable CA, He J, Khandelwal SG, Slonim AD. Pediatric patients hospitalized with myocarditis: a multi-institutional analysis. Pediatr Cardiol. (2010) 31:222-8. doi: 10.1007/s00246-009-9589-9

5. Towbin JA, Lowe AM, Colan SD, Sleeper LA, Orav EJ, Clunie S, et al. Incidence, causes, and outcomes of dilated cardiomyopathy in children. JAMA. (2006) 296:1867-76. doi: 10.1001/jama.296. 15.1867

6. Matsuura H, Ichida F, Saji T, Ogawa S, Waki K, Kaneko M, et al. Clinical features of acute and fulminant myocarditis in children - 2nd nationwide survey by Japanese Society of Pediatric Cardiology and Cardiac Surgery. Circ J. (2016) 80:2362-8. doi: 10.1253/circj.CJ-16-0234

7. Canter CE, Cunningham MW, Cooper LT. Recent clinical and translational research on pediatric myocarditis. Prog Pediatr Cardiol. (2011) 32:15-8. doi: 10.1016/j.ppedcard.2011.06.004

8. Qing-you Z, Jun-bao D. Recent clinical research on glucocorticoids and intravenous immunoglobulin therapy with myocarditis in children. Chin Pediatr Emerg Med. (2013) 20:459-63.

9. Rose NR. Viral myocarditis. Curr Opin Rheumatol. (2016) 28:383-9. doi: 10.1097/BOR.0000000000000303

10. Moher D, Liberati A, Tetzlaff J, Altman DG, The PG. Preferred reporting items for systematic reviews and meta-analyses: the PRISMA statement. PLoS Med. (2009) 6:e1000097. doi: 10.1371/journal.pmed.1000097

11. Aziz KU, Patel N, Sadullah T, Tasneem H, Thawerani H, Talpur S. Acute viral myocarditis: role of immunosuppression: a prospective randomised study. Cardiol Young. (2010) 20:509-15. doi: 10.1017/S1047951110000594

12. Camargo PR, Snitcowsky R, da Luz PL, Mazzieri R, Higuchi ML, Rati M, et al. Favorable effects of immunosuppressive therapy in children with dilated cardiomyopathy and active myocarditis. Pediatr Cardiol. (1995) 16:61-8. doi: 10.1007/BF00796819

13. English RF, Janosky JE, Ettedgui JA, Webber SA. Outcomes for children with acute myocarditis. Cardiol Young. (2004) 14:488-93. doi: 10.1017/S1047951104005049

14. Alrabte S, Bezanti K. Role of intravenous immunoglobulin in the treatment of acute myocarditis. Cardiol Young. (2013) 23:S96. doi: $10.1017 / \mathrm{S} 104795111300036 \mathrm{X}$

15. Atiq M, Hoda M, Aslam N. Effect of intravenous gamma globulin on shortand mid-term clinical outcome in acute viral myocarditis in children. World J Cardiovasc Dis. (2014) 4:39. doi: 10.4236/wjcd.2014.42007

16. Haque A, Bhatti S, Siddiqui FJ. Intravenous immune globulin for severe acute myocarditis in children. Indian Pediatr. (2009) 46:810-1.

17. Heidendael JF, Den Boer SL, Wildenbeest JG, Dalinghaus M, Straver B, Pajkrt D. Intravenous immunoglobulins in children with new onset dilated cardiomyopathy. Cardiol Young. (2018) 28:46-54. doi: $10.1017 /$ S1047951117001561

18. Prasad AN, Chaudhary S. Intravenous immunoglobulin in children with acute myocarditis and/or early dilated cardiomyopathy. Indian Pediatr. (2014) 51:583-4. doi: 10.1007/s13312-014-0456-2

19. Heart Failure Society of America. Section 16: myocarditis: current treatment. J Card Fail. (2006) 12:e120-2. doi: 10.1016/j.cardfail.2005.11.021

20. Canter Charles E, Simpson Kathleen E. Diagnosis and treatment of myocarditis in children in the current era. Circulation. (2014) 129:115-28. doi: 10.1161/CIRCULATIONAHA.113.001372
21. Bern C. Chagas' disease. $N$ Engl J Med. (2015) 373:456-66. doi: 10.1056/NEJMra1410150

22. Sally AH. Viral myocarditis and dilated cardiomyopathy: etiology and pathogenesis. Curr Pharm Des. (2016) 22:408-26. doi: $10.2174 / 1381612822666151222160500$

23. Pollack A, Kontorovich AR, Fuster V, Dec GW. Viral myocarditis-diagnosis, treatment options, and current controversies. Nat Rev Cardiol. (2015) 12:670. doi: $10.1038 /$ nrcardio. 2015.108

24. Frustaci A, Russo MA, Chimenti C. Randomized study on the efficacy of immunosuppressive therapy in patients with virus-negative inflammatory cardiomyopathy: the TIMIC study. Eur Heart J. (2009) 30:1995-2002. doi: 10.1093/eurheartj/ehp249

25. Wojnicz R, Nowalany-Kozielska E, Wojciechowska C, Glanowska G, Wilczewski P, Niklewski $T$, et al. Randomized, placebo-controlled study for immunosuppressive treatment of inflammatory dilated cardiomyopathy: two-year follow-up results. Circulation. (2001) 104:39-45. doi: 10.1161/01.CIR.104.1.39

26. Lu C, Qin F, Yan Y, Liu T, Li J, Chen H. Immunosuppressive treatment for myocarditis: a meta-analysis of randomized controlled trials. J Cardiovasc Med. (2016) 17:631-7. doi: 10.2459/JCM.00000000000 00134

27. Maisch B, Pankuweit S. Current treatment options in (peri)myocarditis and inflammatory cardiomyopathy. Herz. (2012) 37:644-56. doi: $10.1007 /$ s00059-012-3679-9

28. Nimmerjahn F, Ravetch JV. Anti-inflammatory actions of intravenous immunoglobulin. Annu Rev Immunol. (2008) 26:513-33. doi: 10.1146/annurev.immunol.26.021607.090232

29. Maisch B, Alter P. Treatment options in myocarditis and inflammatory cardiomyopathy: focus on i. v. immunoglobulins. Herz. (2018) 43:423-30. doi: 10.1007/s00059-018-4719-x

30. Robinson J, Hartling L, Vandermeer B, Klassen TP. Intravenous immunoglobulin for presumed viral myocarditis in children and adults. Cochrane Database Syst Rev. (2015) 20:CD004370. doi: 10.1002/14651858.CD004370.pub3

31. Amabile N, Fraisse A, Bouvenot J, Chetaille P, Ovaert C. Outcome of acute fulminant myocarditis in children. Heart. (2006) 92:1269-73. doi: 10.1136/hrt.2005.078402

32. Liu C, Chen J, Liu K. Immunosuppressive treatment for inflammatory cardiomyopathy: meta-analysis of randomized controlled trials. Int Heart J. (2005) 46:113-22. doi: 10.1536/ihj.46.113

Conflict of Interest Statement: The authors declare that the research was conducted in the absence of any commercial or financial relationships that could be construed as a potential conflict of interest.

Copyright (c) $2019 \mathrm{Li}, \mathrm{Yu}, \mathrm{Chen}$, Liao and Du. This is an open-access article distributed under the terms of the Creative Commons Attribution License (CC BY). The use, distribution or reproduction in other forums is permitted, provided the original author(s) and the copyright owner(s) are credited and that the original publication in this journal is cited, in accordance with accepted academic practice. No use, distribution or reproduction is permitted which does not comply with these terms. 